OPEN ACCESS

Edited by:

Jose Luis Gonzalez Hernandez, South Dakota State University,

United States

Reviewed by:

Maryke T. Labuschagne, University of the Free State,

South Africa

Yann Manès,

Syngenta Seeds, France

*Correspondence: Leonardo Abdiel Crespo-Herrera

L.Crespo@cgiar.org

Specialty section: This article was submitted to Plant Breeding, a section of the journal

Frontiers in Plant Science

Received: 07 December 2020 Accepted: 06 April 2021

Published: 24 May 2021

Citation:

Crespo-Herrera LA, Crossa J Huerta-Espino J, Mondal S, Velu G, Juliana $P$, Vargas $M$, Pérez-Rodríguez P, Joshi AK Braun HJ and Singh RP (2021) Target Population of Environments for Wheat

Breeding in India: Definition,

Prediction and Genetic Gains.

Front. Plant Sci. 12:638520.

doi: 10.3389/fpls.2021.638520

\title{
Target Population of Environments for Wheat Breeding in India: Definition, Prediction and Genetic Gains
}

\begin{abstract}
Leonardo Abdiel Crespo-Herrera ${ }^{1 *}$, Jose Crossa ${ }^{1,2}$, Julio Huerta-Espino ${ }^{3}$, Suchismita Mondal ${ }^{1}$, Govindan Velu ${ }^{1}$, Philomin Juliana ${ }^{4}$, Mateo Vargas ${ }^{5}$, Paulino Pérez-Rodríguez ${ }^{2}$, Arun Kumar Joshi ${ }^{4}$, Hans Joachim Braun ${ }^{1}$ and Ravi Prakash Singh ${ }^{1}$
\end{abstract}

\begin{abstract}
${ }^{1}$ Global Wheat Program, International Maize and Wheat Improvement Center (CIMMYT), Texcoco, Mexico, ${ }^{2}$ Colegio de Post-Graduados, Texcoco, Mexico, ${ }^{3}$ Instituto Nacional de Investigaciones Forestales, Agricolas y Pecuarias (INIFAP), Campo Experimental Valle de México, México, Mexico, ${ }^{4}$ Global Wheat Program, International Maize and Wheat Improvement Center (CIMMYT), New Delhi, India, ${ }^{5}$ Programa de Protección Vegetal, Universidad Autónoma Chapingo, Texcoco, Mexico
\end{abstract}

In this study, we defined the target population of environments (TPE) for wheat breeding in India, the largest wheat producer in South Asia, and estimated the correlated response to the selection and prediction ability of five selection environments (SEs) in Mexico. We also estimated grain yield (GY) gains in each TPE. Our analysis used meteorological, soil, and GY data from the international Elite Spring Wheat Yield Trials (ESWYT) distributed by the International Maize and Wheat Improvement Center (CIMMYT) from 2001 to 2016. We identified three TPEs: TPE 1, the optimally irrigated Northwestern Plain Zone; TPE 2, the optimally irrigated, heat-stressed North Eastern Plains Zone; and TPE 3, the drought-stressed Central-Peninsular Zone. The correlated response to selection ranged from 0.4 to 0.9 within each TPE. The highest prediction accuracies for GY per TPE were derived using models that included genotype-byenvironment interaction and/or meteorological information and their interaction with the lines. The highest prediction accuracies for TPEs 1, 2, and 3 were 0.37, 0.46, and 0.51, respectively, and the respective GY gains were 118, 46, and $123 \mathrm{~kg} / \mathrm{ha} /$ year. These results can help fine-tune the breeding of elite wheat germplasm with stable yields to reduce farmers' risk from year-to-year environmental variation in India's wheat lands, which cover 30 million ha, account for 100 million tons of grain or more each year, and provide food and livelihoods for hundreds of millions of farmers and consumers in South Asia.

Keywords: genotype-by-environment interaction, response to selection, genetic correlations, multienvironmental trials, pedigree-based predictions

\section{INTRODUCTION}

Among the world's three most important staple food crops, wheat is grown on more than 215 million hectares (ha) worldwide, producing over 735 million tons (t) of grain (USDA, 2020). In South Asia, wheat is consumed by more than 1.8 billion people and is grown on about 47 million ha with an annual production of almost 145 million $t$ (USDA, 2020). More specifically, India is the 
region's largest wheat producer, with 30 million ha of wheat area accounting for 107 million $t$ of grain (USDA, 2020).

The International Maize and Wheat Improvement Center (CIMMYT) annually develops and distributes improved wheat germplasm to hundreds of partners worldwide, free of charge in the form of targeted yield trials and observation nurseries. Recipients grow the trials and nurseries, keep promising lines for their breeding programs or for direct release and are asked to return performance data that are collectively interpreted and shared to guide further breeding. The data reflect significant variations in growing environments across years and locations and serve as an input for CIMMYT wheat breeding, resulting in lines that are diverse and specially selected for yield potential, disease resistance, end-use quality, and climate resilience. Research has shown that conditions at the CIMMYT wheat research station near Ciudad Obregón, an irrigated desert farm in northwestern Mexico, correlate with diverse wheat-growing environments worldwide (DeLacy et al., 1993; Lillemo et al., 2005) and, by controlling irrigation, create a simulation of six selection environments (SEs) that represent major CIMMYT target regions for wheat breeding and deployment in the developing world.

As part of CIMMYT's efforts to describe, measure, and analyze genotype $\times$ environment (GE) interaction in the multienvironment testing of wheat lines, Cooper and DeLacy (1994) identified three areas: analysis of variance, indirect selection, and pattern analysis. Pattern analyses in the form of classification and ordination methods (Cooper and Hammer, 1996) involve developing biplots for the first two or three principal components for lines and environments to portray the relationships among environments, whereby the representation of discrimination among lines from the classification can be superimposed on the low-dimensional space defined by the ordination. Statistical applications by CIMMYT and partners to assess GE in extensive international wheat trials found that CIMMYT's main testing location can be associated with various international sites (Crossa, 1990; Crossa et al., 1991; Cooper et al., 1993a,b,c,d) within certain mega-environments (MEs) that represent the world's major wheat-producing areas (Rajaram et al., 1994; Braun et al., 1996).

A target population of environments (TPE) is a variable group of future production environments. A TPE is composed of many environments and future years or growing seasons. Naturally, GE may result from relatively static and predictable variationfor example, in soil or other conditions across the fieldand dynamic, unpredictable, and often significant temporal variability-i.e., weather over different years.

The TPE delineations are based on climate, soil, and hydrological characteristics and can also include socioeconomic features, such as the resource levels of farm households. There are also different ways to group trials and environments into a TPE. Data from environmental sensors and satellites can be used to develop stratified hierarchical cluster analyses (Cooper and Hammer, 1996) of sites and thus identify homogeneous environments wherein line performances will be highly correlated.
SEs are where a breeder selects lines. The SE is identified as predicting the performance in a given TPE, but the SE may not itself belong to the TPE. To determine if lines tested in the SE are useful to predict the performance of those in the TPE, it is important to (1) compute the genetic correlations between the lines in the SE vs. the same (or related) lines in the TPE and show relatively high correlations between performances in both; (2) screen lines in the SE, with the repeatability (broad-sense heritability), where the SE is higher than the TPE; and (3) ensure that the $\mathrm{SE}$ allows a large number of lines to be screened at a low cost, such that the SE provides a high selection intensity.

In this study, we aimed to define TPEs for wheat breeding in India using historical meteorological and soil data and to estimate the genetic correlation, the direct and correlated response to selection between the TPEs and the SE of Ciudad Obregón, the prediction ability of the SE in Mexico, and the grain yield (GY) gains in each TPE over time.

\section{MATERIALS AND METHODS}

\section{Data}

We used GY data from crop cycles 2001-2002 to 2016-2017 of Elite Spring Wheat Yield Trials (ESWYT) nurseries tested in India and at the CIMMYT-Ciudad Obregón research station $\left(27^{\circ}\right.$ $37^{\prime} \mathrm{N}$, altitude 39 masl, average annual rainfall $330 \mathrm{~mm}$ ). Trials were conducted under five SEs:

(1) Beds with five irrigations (B5IR): Trials were grown on raised beds with full (optimal) irrigation, meaning about $500 \mathrm{~mm}$ of available water and an optimal sowing date of late November-mid December.

(2) Flat five irrigations (F5IR): Trials grown on the flat with optimal irrigation and optimal sowing date.

(3) Beds with two irrigations (B2IR). Trials were grown on raised beds with partial irrigation of about $260 \mathrm{~mm}$ of available water and optimal sowing date.

(4) Flat drought (FDRT): Planted trials were grown on the flat with about $180 \mathrm{~mm}$ of available water, creating severe drought conditions, and optimal sowing date.

(5) Beds late heat (BLHT): Trials were sown in February, a nonoptimal planting month that subjects the crop to terminal heat stress, and optimally irrigated.

The 41 trial locations across India (Table 1) provided 245 siteyear combinations. The ESWYT is distributed yearly on request and consists of 49 genotypes plus a local check included by cooperators at the trial site. The genotypes included are selected after 2 or 3 years of testing at CIMMYT-Ciudad Obregón. CIMMYT generates some 9,000 new wheat lines each year that are tested between November and April under optimal conditions (Stage 1) at the Ciudad Obregón station. From those, 1,000 selected lines are tested in six simulated environments (Stage 2) that include varying levels of drought and high-temperature stress, as well as optimal conditions. About 250 lines from Stage 2 are advanced for further testing in three of the six simulated environments (Stage 3). At that point, seed from the lines is also multiplied in a Karnal bunt-free area in Mexico for use in ESWYT 
and other trials and nurseries. ESWYT entries change each year, resulting in a lack of connectivity between years of evaluation. Data are not provided for 2002-2004 because the trials were not grown in the described SEs in those years.

\section{Definition of the Target Population of Environments}

Daily data from 2003 to 2016 for nine meteorological variables (MVs) for locations in India (Table 1) were obtained from the NASA Langley Research Center (LaRC) POWER Project funded through the NASA Earth Science/Applied Science Program. In addition, nine soil-related variables (SVs) for each location were obtained through the Soil Grids application of the International Soil Reference and Information Centre. The MVs and SVs are listed in Table 2. Each MV was averaged over periods of 20 days starting from November 23 each year and reaching 120 days. The starting date used was the median in the range of planting dates in India.

For each location, $63 \mathrm{MV}$ and SV variables were used for principal component analysis (PCA) with the correlation matrix of the data to infer the number of groups (TPEs) that explain most of the variation. We then conducted hierarchical clustering of the groups based on Euclidean distance, according to Ward (1963). The cluster solution (k) was equal to the number of groups identified in the PCA.

The TPEs were plotted on a map of India and interpolated by fitting a Thin Plate Spline regression (Wood, 2003), with a model to fit:

$$
y_{i}=f\left(x_{i}\right)+\varepsilon_{i}
$$

where $y_{i}$ is the response variable, $x_{i}$ are covariates, $f()$ is a $d$ dimensional surface smoothing function, and $\varepsilon_{i}^{\prime} s$ are model residuals distributed as independent and identically distributed random variables with mean 0 and variance $\sigma^{2}$. Thin plate splines were used to estimate $f$ by finding the function $g$ that minimizes:

$$
\|\mathbf{y}-\mathbf{g}\|^{2}+\lambda J_{m d}(g)
$$

where $\mathbf{y}$ is the vector of data, $\mathbf{g}=\left(g\left(x_{1}\right), g\left(x_{2}\right) g\left(x_{3}\right), \ldots, g\left(x_{n}\right)\right)^{\prime}, \quad J_{m d}(g)$ is a penalty functional that measures the change of $g$, and $\lambda$ is a smoothing parameter.

\section{Trial Analysis in India Target Population of Environments}

After defining India TPEs using environmental data, we performed a multi-environment trial analysis of GY by year and TPE. The following model was used to estimate variance components:

$$
\mathbf{y}=\mu+\mathbf{E}_{\mathbf{s}}+\mathbf{R}_{\mathbf{j}}+\mathbf{R}_{\mathbf{j}}\left(\mathbf{E}_{\mathbf{s}}\right)+\mathbf{G}_{\mathbf{i}}+\mathbf{G} E_{\mathbf{i} j}+\varepsilon_{i j s}
$$

where $\mu$ is the general mean, $\mathbf{E}_{\mathbf{s}}$ is the fixed effect of the environments $(s=1, \ldots, n), \mathbf{R}_{\mathbf{j}}$ is the random effects of the replicates $(j=1,2), \mathbf{G}_{\mathbf{i}}$ is the random effects of the genotypes $(i=1, \ldots, 50), \mathbf{G} E_{\mathbf{i} j}$ represents the random effect of GE interaction, and $\varepsilon_{i j k}$ is a random residual assumed to be independently, identically, and normally distributed (IID) with mean zero and variance $\sigma_{e}^{2}$.

Additionally, we fitted another mixed model to include the TPEs as a fixed effect with:

$$
\mathbf{y}=\mu+\mathbf{T} P E_{\mathbf{k}}+\mathbf{G}_{\mathbf{i}}+\mathbf{G} * \mathbf{T} P E_{\mathbf{i} k}+\mathbf{G} * \mathbf{E}_{\mathbf{i} s}\left(\mathbf{T} P E_{\mathbf{k}}\right)+\mathbf{E}_{\mathbf{s}}\left(\mathbf{T} P E_{\mathbf{k}}\right)+
$$

$$
\mathbf{R}_{\mathbf{j}}\left(\mathbf{E}_{\mathbf{s}}\right)+\mathbf{S} B_{\mathbf{l}}\left(\mathbf{E} * \mathbf{R}_{\mathbf{s} j}\right)+\varepsilon_{i j k l s}
$$

where $\mathbf{T} P E_{\mathbf{k}}$ is the fixed effect of the TPEs $(\mathrm{k}=1,2,3)$, and $\mathbf{S} B_{1}$ represents the random effects of sub-blocks in the alphalattice design $(1=1, \ldots, 5)$, and the remaining terms are as in Equation (3).

The broad-sense heritability $\left(H^{2}\right)$ of the trials across environments in each TPE-year combination and across environments, and TPE was calculated with Equations (5) and (6), respectively:

$$
\begin{gathered}
H^{2}=\frac{V_{g}}{V_{g}+\frac{V_{g e}}{n e}+\frac{V_{r}}{n r \times n e}} \\
H^{2}=\frac{V_{g}+V_{g * t p e}}{V_{g}+V_{g * t p e}+\frac{V_{g e(t p e)}}{n e} \frac{V_{r}}{n r \times n e}}
\end{gathered}
$$

where $V_{g}$ represents the genotypic variance, $V_{g e}$ represents the GE variance, $V_{r}$ is the residual variance, and $n e$ and $n r$ are the number of environments and replicates, respectively. In Equation (6), $V_{t p e * g}$ represents genotype $\times$ TPE variance, $V_{g e(t p e)}$ is the variance of the GE within TPEs.

\section{Trial Analyses in Selection Environments of Mexico}

The trials conducted in the SEs were analyzed individually with the following model:

$$
\mathbf{y}=\mu+\mathbf{R}_{\mathbf{j}}+\mathbf{S B}_{\mathbf{k}}\left(\mathbf{R}_{\mathbf{j}}\right)+\mathbf{G}_{\mathbf{i}}+\varepsilon_{i j k}
$$

where $\mu$ is the general mean, $\mathbf{G}_{\mathbf{i}}$ is the random effects of the genotypes $(i=1, \ldots, 50), \mathbf{R}_{\mathbf{j}}$ is the random effects of the replicates $(j=1,2), \mathbf{S B}_{\mathbf{k}}$ denotes the random effects of the sub-blocks $(k=1$, ...,5) assumed to be independently, identically, and normally distributed (IID) with mean zero and variance $\sigma^{2} s b(r)$, and $\varepsilon_{i j k}$ is a random residual assumed to be IID with mean zero and variance $\sigma_{e}^{2}$. The results from this model were used to conduct pedigree-based predictions.

The mixed model fit for the across-SE analysis was:

$$
\mathbf{y}=\mu+\mathbf{S} E_{\mathbf{s}}+\mathbf{R}_{\mathbf{j}}+\mathbf{R} * \mathbf{S} B_{\mathbf{j} k}\left(\mathbf{S} E_{\mathbf{s}}\right)+\mathbf{G}_{\mathbf{i}}+\mathbf{G} * \mathbf{S} E_{\mathbf{i} s}+\varepsilon_{i j k s}
$$

where $\mathbf{S} E_{\mathbf{j}}$ represents the SEs $(s=1, \ldots, 5)$, and the remaining terms are as in Equation (7).

The heritability of trials in SE in Equation (8) was estimated with Equation (5), but replacing $V_{g e}$ with the genotype $\times \mathrm{SE}$ interaction and ne with the number of SE. 
TABLE 1 | Locations in India considered for the definition of Target Population of Environments (TPE) with Elite Spring Wheat Yield Trials (ESWYT) germplasm.

\begin{tabular}{|c|c|c|c|c|}
\hline Description & Institute name & Latitude & Longitude & TPE \\
\hline Chandpa_GKSPL & Ganga Kaveri Seeds Pvt Ltd. & 27.58 & 78.05 & 1 \\
\hline DWR_dplantbreedingg & DWR & 32.1 & 76.05 & 1 \\
\hline DWR_Karnal1 & SKUAST-J & 29.67 & 77.03 & 1 \\
\hline DWR_Karnal2 & DWR & 29.67 & 76.97 & 1 \\
\hline Hissar & CCS Haryana Agricultural Univ. & 29.17 & 75.77 & 1 \\
\hline Jalander_SB & Bioseed Research India Ltd. & 30.90 & 75.8 & 1 \\
\hline Ludh_BISA & BISA & 30.95 & 75.88 & 1 \\
\hline Mahyco & MAHYCO & 29.95 & 76.88 & 1 \\
\hline Naruana_MHS & MAHYCO & 30.2 & 74.93 & 1 \\
\hline Newdelhi_|ARI & |ARI-Div. Of Genetics & 28.58 & 77.2 & 1 \\
\hline NSL_Guargaon & Nuziveedu Seeds Ltd. & 28.62 & 77.07 & 1 \\
\hline Pantnagar & G.B. Pant Univ. Of Agr. & 29 & 79.5 & 1 \\
\hline PAU_Gurdaspur & Punjab Agricultural University & 32.03 & 75.4 & 1 \\
\hline PAU_Ludh & Bioseed Research India Ltd. & 30.93 & 75.87 & 1 \\
\hline Syngenta_Karnal & Syngenta India Limited & 29.63 & 75.1 & 1 \\
\hline Azadu_ATK & C.S.S. Research Institute & 26.47 & 80.4 & 2 \\
\hline BAU_Ranchi & DWR & 23.35 & 85.32 & 2 \\
\hline Bhagalpur & Bihar Agricultural University & 25.23 & 87.07 & 2 \\
\hline $\mathrm{BHU}$ & Banaras Hindu University & 25.3 & 83.05 & 2 \\
\hline Ghajipur & S.D. Agricultural University & 26.78 & 82.2 & 2 \\
\hline IARI_PUSA & Univ. Of Ag. \& Tech. & 25.87 & 85.8 & 2 \\
\hline IRRS_Bilaspur & Birsa Agricultural University & 22.15 & 82.2 & 2 \\
\hline Pusa_BISA & BISA & 25.88 & 85.82 & 2 \\
\hline AFH_Pune & Agharkar Res. Institute & 18.07 & 74.35 & 3 \\
\hline Ankurrfk_Nagpur & Ankur Seeds Pvt. Ltd. & 21.15 & 79.15 & 3 \\
\hline ARI_Jaipur & Agharkar Res. Institute & 26.97 & 75.8 & 3 \\
\hline Dbotany & Deemed University & 27.98 & 78.97 & 3 \\
\hline GAU_Junagadh & Junagarh Agricultural Univ. & 21.5 & 70.48 & 3 \\
\hline GAU_Vijapur & S.D. Agricultural University & 23.58 & 72.75 & 3 \\
\hline Gokulwadi_Jalna & Krishidhan Seeds Private Ltd. & 19.85 & 75.88 & 3 \\
\hline Gwalior & DWR & 26.22 & 78.23 & 3 \\
\hline Hoshangabad & Junagarh Agricultural Univ. & 22.73 & 77.7 & 3 \\
\hline Indore & $|A R|$ & 22.62 & 75.83 & 3 \\
\hline ITC_Vidisha & ITC Life Scs \& Technology Ctr & 23.52 & 77.82 & 3 \\
\hline Jab_BISA & BISA & 23.17 & 79.98 & 3 \\
\hline Jabalpur_LFJ & JNKW & 23.15 & 79.97 & 3 \\
\hline KSPL_Ganhinagar & Krishidhan Seeds Pvt. Ltd. & 23.25 & 72.75 & 3 \\
\hline MPKV_Niphad & Mahatma Phule Krishi Vidyapeet & 20.1 & 74.1 & 3 \\
\hline RDW_ugarsugar & Univ. Of Agr. Scs. & 15.73 & 75.18 & 3 \\
\hline UAS_Dharwad & Univ. Of Agric. Sciences & 15.7 & 76.12 & 3 \\
\hline UGAR_SUGAR_FRF & Univ. Of Agric. Sciences & 15.43 & 75.12 & 3 \\
\hline
\end{tabular}

\section{Correlation Between Target Population of Environments and Selection Environment}

Once we determined variance components by year, across sites in TPEs, and across SE and averaged them across years, the same models were fitted using the genotypes and the GE for TPEs as fixed effects to make best linear unbiased estimations (BLUEs) and subsequently calculate Pearson's correlation coefficient between each TPE-year combination and across SE-year combinations. The respective estimation of genetic correlations was then computed according to Cooper and DeLacy (1994):

$$
r_{i j}=\frac{p_{i j}}{\sqrt{h_{i}^{2} \times h_{j}^{2}}}
$$

where $r_{i j}$ is the genetic correlation, $p_{i j}$ represents the phenotypic correlation between environments or groups of environments $i$ and $j$, and $h_{i}^{2}$ and $h_{j}^{2}$ are the heritability of environments or groups of environments $i$ and $j$, respectively. 
TABLE 2 | Meteorological variables (MVs) and soil-related variables (SVs) considered for Target Population of Environments (TPE) definition in India.

\begin{tabular}{|c|c|c|c|c|c|}
\hline \multirow[b]{2}{*}{ Type } & \multirow[b]{2}{*}{ Variable } & \multirow[b]{2}{*}{ Units } & \multicolumn{3}{|c|}{ TPE } \\
\hline & & & 1 & 2 & 3 \\
\hline MV & Average temperature at two meters & ${ }^{\circ} \mathrm{C}$ & 15.82 & 18.7 & 21.43 \\
\hline MV & Maximum temperature at two meters & ${ }^{\circ} \mathrm{C}$ & 24.26 & 27.27 & 30.69 \\
\hline MV & Minimum temperature at two meters & ${ }^{\circ} \mathrm{C}$ & 9.5 & 11.69 & 13.72 \\
\hline MV & Cooling degree days & ${ }^{\circ} \mathrm{C}-\mathrm{d}$ above $0{ }^{\circ} \mathrm{C}$ & 16.88 & 19.48 & 22.2 \\
\hline MV & Dew point & ${ }^{\circ} \mathrm{C}$ & 0.65 & 6.18 & 4.24 \\
\hline MV & Precipitation & $\mathrm{mm}$ & 12.76 & 7.83 & 4.37 \\
\hline MV & Relative humidity at two meters & $\ln \%$ & 38.29 & 46.87 & 35.77 \\
\hline MV & Clear sky insolation incident on a horizontal surface & $\mathrm{kW}-\mathrm{h} / \mathrm{m}^{2} /$ day & -18.47 & -13.12 & 7.68 \\
\hline MV & Wind speed at two meters & $\mathrm{m} / \mathrm{s}$ & 1.59 & 1.68 & 1.86 \\
\hline SV & Available soil water capacity & Volumetric fraction in \% & 15.2 & 13.12 & 8.72 \\
\hline SV & Available soil water capacity until wilting point & Volumetric fraction in \% & 20.4 & 22.87 & 27.5 \\
\hline SV & Cation exchange capacity of soil & $\mathrm{cmolc} / \mathrm{kg}$ & 14.47 & 18.75 & 35.5 \\
\hline SV & Coarse fragments volumetric & $\ln \%$ & 5.467 & 7.75 & 15.4 \\
\hline SV & Soil organic carbon density & $\mathrm{kg} / \mathrm{m}^{3}$ & 94.27 & 118.37 & 124 \\
\hline SV & Soil pH in $\mathrm{H}_{2} \mathrm{O}$ & $\mathrm{pH}$ & 7.53 & 6.91 & 7.43 \\
\hline SV & Clay content $(0-2 \mu \mathrm{m})$ & Mass fraction in \% & 25.2 & 30 & 40.4 \\
\hline SV & Sand content (50-2,000 $\mu \mathrm{m})$ & Mass fraction in \% & 37.4 & 32.2 & 32.3 \\
\hline SV & Silt content $(2-50 \mu \mathrm{m})$ & Mass fraction in \% & 37.4 & 38 & 27.5 \\
\hline
\end{tabular}

\section{Estimation of the Correlated and Direct Response to Selection}

Once the genetic correlation by year was estimated, and assuming the same selection intensity in TPE and SE, the correlated response to selection $(C R)$ was then calculated following Falconer (1952) and Searle (1965):

$$
C R=\bar{r} \times \sqrt{\frac{H_{S E}^{2}}{H_{T P E}^{2}}}
$$

where $\bar{r}$ is the average genetic correlation (Equation 9) of years of testing between TPEs and across SEs, $H_{S E}^{2}$ is the broadsense heritability across the SE, and $H_{T P E}^{2}$ is the broad-sense heritability across sites of the TPE. Both heritability terms in Equation (7) were averaged over years of testing in TPEs and SEs. The correlated response (CR) measures the relative efficiency of selecting indirectly for the TPEs by using the information across SE.

The expected direct response to selection $(D R)$ across sites without considering TPEs, across SEs, and across sites in each TPE was estimated with Equation (11), dividing the genetic variance by the square root of phenotypic variance, disregarding selection intensity $(i=1)$.

$$
D R=i \frac{V_{g}}{\sqrt{V_{g}+\frac{V_{g e}}{n e}}+\frac{V_{r}}{n e \times n r}}
$$

where the variance terms represent the same as those in Equation (5). The DR measures the estimated response in the TPE or across SEs by directly selecting in those same environments.

\section{Pedigree-Based Predictions of India Target Population of Environments Using the Mexico Selection Environment}

We estimated the pedigree-based prediction accuracy of the Mexico SE for the 2016 cycle of the ESWYT in each TPE. The training population consisted of the lines in Stage 1 that were selected for Stages 2 and 3 plus their subsequent evaluations in the last two stages of yield testing in the SE. We also incorporated the ESWYT data from each SE and TPE over 2010-2015. The preceding gave a total of 3,599 unique lines and 22,872 line-yearenvironment combinations.

We used three models to predict the performance of the wheat lines at Indian sites of the TPE using Mexico's SE.

\section{Model 1 (AE)}

This model incorporates random effects of the pedigree information along with environments:

$$
y_{i j}=\mu+E_{i}+a_{j}++\varepsilon_{i j}
$$

where $E_{i}$ is the random effect of environment (TPE/SE-year combination), assumed to be IID with mean zero and variance $\sigma_{E}^{2} ; a_{j}$ is the random effect of lines with the pedigree information we assume $\mathbf{a} \sim \operatorname{MN}\left(\mathbf{0}, \sigma_{a}^{2} \mathbf{A}\right)$, where $\sigma_{a}^{2}$ is the additive variance parameter, $A$ is the additive relationship matrix derived from pedigree, and $M N$ stands for multivariate normal. The additive relationship matrix was calculated with the $\mathrm{R}$ package pedigree (Coster, 2012). 


\section{Model 2 (AE-AxE)}

We added the random effect of the interaction between lines and environments to Model 1:

$$
y_{i j}=\mu+E_{i}+a_{j}+a E_{i j}++\varepsilon_{i j},
$$

where $A E_{i j}$ is the random effect of the interaction between lines and environments, assuming that the joint distribution of interaction vector $\mathbf{a} E \sim \operatorname{MN}\left(\left(\mathbf{0}, \mathbf{Z}_{p} \mathbf{A} \mathbf{Z}_{p}^{\prime}\right)^{\circ}\left(\mathbf{Z}_{E} \mathbf{Z}_{E}^{\prime}\right) \sigma_{a E}^{2}\right)$, where $\mathbf{Z}_{p}$ is the matrix linking the phenotypic entries with the pedigree information, $\mathbf{Z}_{E}$ is the incidence matrix of environmental effects, and ${ }^{\circ}$ represents the Hadamard product between matrices to impose the reaction norm structure on GE (Jarquín et al., 2014; Pérez-Rodríguez et al., 2015).

\section{Model 3 (AE-AxE-W-AxW)}

Model 3 is an extension of Model 2 that incorporates an additional random effect of MVs and their interactions with the lines of each TPE.

$$
y_{i j}=\mu+E_{i}+a_{j}+a E_{i j}+t_{i j}+a t_{i j}+\varepsilon_{i j},
$$

where $t_{i j}=\sum_{q} W_{i j q} \gamma_{q}$ with $\mathbf{W}$ being a matrix of environmental covariates and $\gamma_{q}$ representing the effect of the environmental covariates, which we assume as independent and identically distributed random variables with mean zero and variance $\sigma_{\gamma}^{2}$, and we further assume that $\mathbf{a} t \sim \operatorname{MN}\left(\mathbf{0},\left(\mathbf{Z}_{\mathbf{p}} \mathbf{A} \mathbf{Z}_{\mathbf{p}}^{\prime}\right)^{\circ}\left(\mathbf{W} \mathbf{W}^{\prime}\right) \sigma_{a w}^{2}\right)$ (Jarquín et al., 2014; Pérez-Rodríguez et al., 2015).

In our implementation, phenotypic data and MVs were centered and scaled to unit variance. The models were run in the BGLR (Pérez and de los Campos, 2014) package for $\mathrm{R}$ (R Development Core Team, 2020). The Pearson's correlation coefficient between the predicted and observed values in the TPE were used as an indicator of the predictive ability of the SEs for each model.

\section{Grain Yield Gain Estimations in Target Population of Environments}

We used the BLUEs from Equation (3) to fit the reaction norm model from Equation (12) with the additive relationship matrix and then regressed the best linear unbiased predictions (BLUPs) from Equation (12) for each TPE in India on the years when ESWYTs were grown. The slope of the regression was taken as the gain in GY in TPEs.

\section{RESULTS}

\section{Definition of Target Population of Environments}

From the analysis of MVs and SVs, we obtained three main clusters (TPEs) of locations (Figure 1) that explained most of the variations $(>70 \%)$ in the data set (Table $\mathbf{1}$ and Figure 2). These TPEs tended to be concentrated in three main geographical zones of India: TPE 1, representing the Northwestern Plain Zone (NWPZ); TPE 2, the North Eastern Plains Zone (NEPZ); and TPE 3, the Central-Peninsular Zone (CPZ) (Figure 2). The respective proportion of sites in each TPE above was $36.6,19.5$, and $43.9 \%$.
Average temperatures were lowest in TPE 1 (about $16^{\circ} \mathrm{C}$ ) and highest in TPE 3 (about $21^{\circ} \mathrm{C}$ ), with TPE 2 in between the two (about $19^{\circ} \mathrm{C}$ ) (Table 2). Cooling degree days and dew point followed a similar pattern (TPE $1<\mathrm{TPE} 2<\mathrm{TPE} 3$ ).

The average accumulated precipitation during the period was roughly $12.8,7.8$, and $4.4 \mathrm{~mm}$ for TPEs 1,2 , and 3 , respectively (Table 2). Average relative humidity was highest in TPE 2 (47\%) and recorded at 38 and $36 \%$ in TPEs 1 and 3, respectively. Clear sky insolation incidence $\left(\mathrm{kW}-\mathrm{h} / \mathrm{m}^{2} /\right.$ day) was $-18.47,-13.12$, and 7.68, for TPEs 1, 2, and 3, respectively. Average wind speed at $2 \mathrm{~m}$ height did not exceed $2 \mathrm{~m} / \mathrm{s}$ in the three TPEs.

Regarding soil conditions (Table 2), the average available soil water capacity was highest in TPE 1 (15\%) and lowest in TPE 3 (9\%), whereas available soil water capacity at wilting point was highest in TPE 3 (28\%) and lowest in TPE 1 (20\%). The average cation exchange capacity was at its highest in TPE $3(35.5 \mathrm{cmolc} / \mathrm{kg})$ - roughly double the values in the other TPEs-a similar pattern was observed for coarse fragments (TPE 3: 15\%); TPE 3 also had the greatest soil organic carbon density (124\%), although the values for TPEs 2 and 1 followed closely. Soil water $\mathrm{pH}$ ranged from 7.75 (TPE 1) to 6.92 (TPE 2). Soil texture compositions (clay-sand-silt) were fairly balanced and differed slightly for TPEs, with TPE 3 having more clayey soils.

\section{Variance Components, Genetic Correlations, and Correlated and Direct Response to Selection}

Average GYs across years and sites ranged from 3.7 t/ha (TPE 2) to $5.1 \mathrm{t} / \mathrm{ha}$ (TPE 1). The average GY across sites for India was $4.7 \mathrm{t} / \mathrm{ha}$, whereas the average GYs across years and SE were 7.1, 4.8, 3.7, 6.7, and 2.5 t/ha for B5IR, B2IR, BLHT, F5IR, and FDRT, respectively.

The average of the variance components indicates that the size of the $G^{*} T P E$ variance relative to that of the $G^{*} E(T P E)$ was $7.3 \%$. The size of the variance of $\mathrm{G}^{*} \mathrm{E}(\mathrm{TPE})$ relative to the genotypes $(G)$ was $518 \%$ (Table 3 ). The size of the $\mathrm{G}^{*}$ TPE variance was $38 \%$ of the $\mathrm{G}$ variance. The $H^{2}$ estimated from the average of the variance components was 0.72 , and the average $D R$ estimated from the variance components was 0.18 (Table 3).

On the other hand, the relative size of the variance of $\mathrm{G}$ in each TPE to that of the across-site analysis was 1.8, 2.4, and 1.1 times higher in TPEs 1, 2, and 3, respectively (Tables 3, 4). The size of the $\mathrm{G}^{*} \mathrm{E}$ variance in each TPE relative to that of $G$ in its respective TPE was 290, 184, and $421 \%$ times higher. The average phenotypic and genetic correlation between TPEs was low and medium size, respectively, ranging from 0.26 to 0.31 (phenotypic) and 0.56 to 0.63 (genetic) (Table 5).

Regarding variance components across SEs (Table 6), the variance of $G$ is 2.3 times higher than that of $G^{*} S E$ (Table 6). Also, $\mathrm{G}$ is 3.3 times greater than the one across sites of the TPEs, and its size relative to each TPE was 1.8, 1.4, and 3.1 for TPEs 1 , 2 , and 3 , respectively (Tables 4,6 ). The $H^{2}$ estimated from the average variance components was 0.73 , which is about the same 


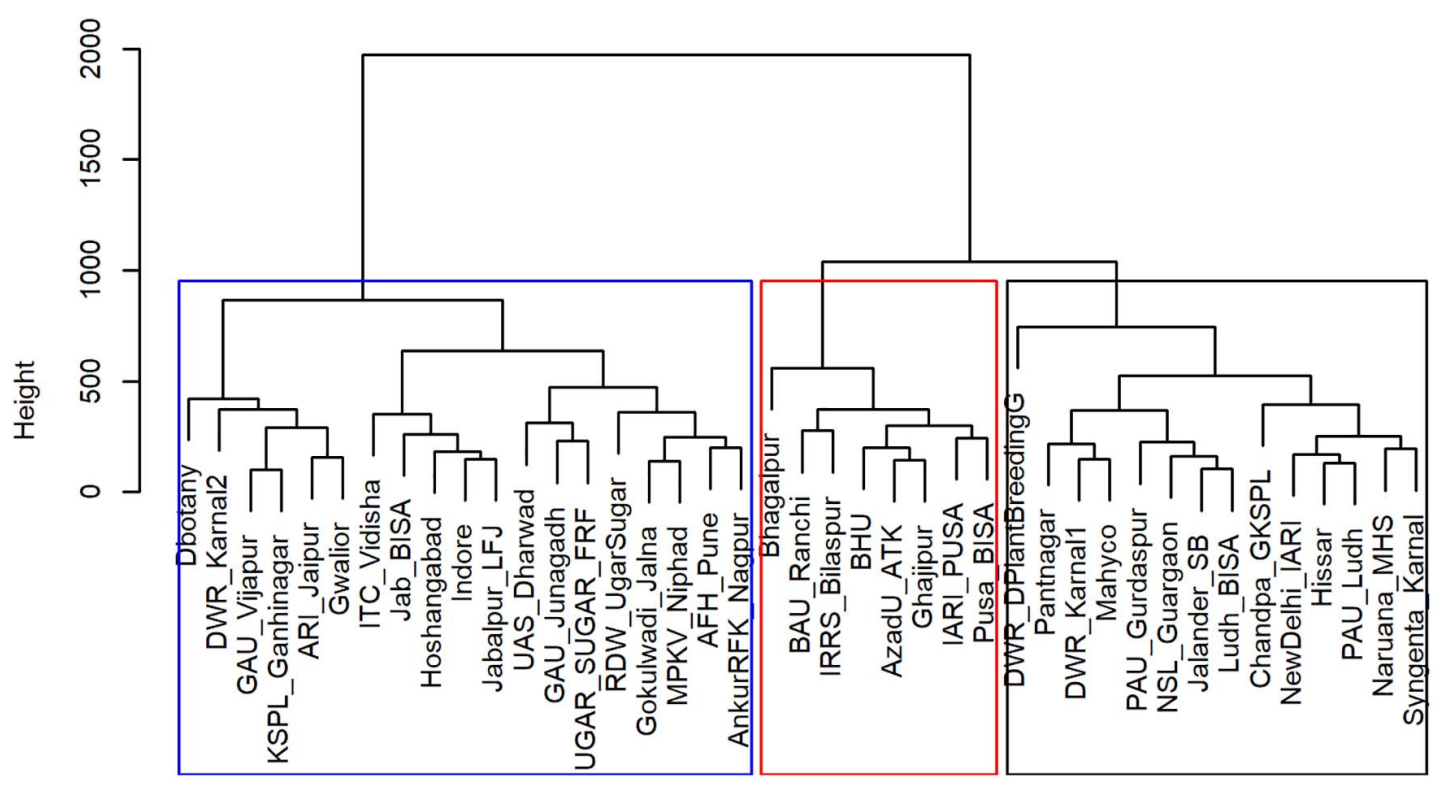

FIGURE 1 | Hierarchical clustering of Elite Spring Wheat Yield Trials sites in India based on meteorological and soil variables.

as the one across all sites in the TPEs, and the magnitude of $H^{2}$ in the SEs relative to TPEs 1,2 , and 3 was, respectively $1.2,2.1$, and 2.1 times higher. The estimated DR across SE was 0.28 , which is 1.6 times higher than that of the DR across TPEs, whereas it was 1.6, 1.7, and 2.5 times higher than that of the TPEs 1,2 , and 3 , respectively (Tables 6, 7).

We ran the model across all sites in India, i.e., disregarding TPE subdivision, and found that the average $H^{2}$ was 0.2 and the DR was 0.16 . The average $H^{2}$ for TPEs 1,2 , and 3 was $0.54,0.39$, and 0.38 , respectively, whereas the respective DRs were $0.17,0.16$, and 0.11 (Table 7 ). The average relative selection efficiencies (CR) across SEs in each TPE were 0.6, 0.9, 0.4 , and 0.5 for TPEs $1,2,3$, and across TPEs, respectively (Tables 3, 7).

\section{Pedigree-Based Predictions}

The proportion of additive variance relative to the total of the prediction models for each SE ranged from 1.6 to $7.9 \%$ (Table 8). The proportion of variance relative to the total (PVT) for environments varied by SE, but it remained close to $90 \%$ when the models did not include environmental covariable data or their interaction with genotypes. Inclusion of MV data reduced the PVT for the main effects of environments in all cases, which was substantial for treatments B5IR (from 92.3 to 43.2\%), F5IR (from 91.7 to $41.7 \%$ ), and FDRT (from 89.7 to 59.9\%). In all cases, the PVTs of GEs were lower than $10 \%$ and ranged from 1.6 to $9.2 \%$ (Table 8). The PVTs of the MVs ranged from $0.2 \%$ (BLHT) to $47.8 \%$ (F5IR). The reduction in residual variance ranged from $34 \%$ (B2IR) to $56 \%$ (FDRT) in models that included the GE.

The predictive correlations - that is, prediction accuracies-of each SE for each TPE in the 2016 ESWYT cycle are shown in Figure 3. SEs B5IR, B2IR, and FDRT were better predictors for
TPE 1. The predictive correlation of B5IR was higher for model AE-AxE-W-AxW (0.28), whereas the predictive correlation of B2IR was higher for model AE-AxE (0.36). No clear increase in predictive correlation was observed for TPE 1 when MV data were included in the model (Figure 3).

For TPE 2, in all SEs except for B5IR, the predictive correlation increased when all available information was included in the prediction model (Figure 3). The prediction accuracies between B2IR, BLHT, F5IR, and FDRT and TPE 2 were 0.4, 0.24, 0.39, and 0.36 , respectively, for model AE-AxE, whereas for model AE-AxE-W-AxW, respective prediction accuracies for TPE 2 were $0.45,0.25,0.46$, and 0.4 . For TPE 3 , predictive correlations with all SEs were positive (Figure 3). In all cases except B2IR, the predictive correlation increased with the inclusion of GE and/or MV data. The prediction accuracies for the AE-AxE model between B5IR, B2IR, BLHT, F5IR, and FDRT and TPE 3 were $0.51,0.36,0.39,0.29$, and 0.19 , respectively, whereas for the AE-AxE-W-AxW, they were 0.51,0.36, 0.39, 0.3, and 0.2 , respectively.

\section{Grain Yield Progress in Target Population of Environments}

The respective rates of GY gain for ESWYT germplasm in India for TPEs 1, 2, and 3 were $118 \mathrm{~kg} / \mathrm{ha} /$ year (Figures 4A,B), $46 \mathrm{~kg} / \mathrm{ha} /$ year (Figures 4C,D), and $123 \mathrm{~kg} / \mathrm{ha} /$ year (Figures 4E,F). In all cases, the regression slope was significantly different from zero $(P<0.0001$; Figure 4). For TPE 2, the R-squared of the regression was 0.07 , providing a less clear pattern (Figures 4C,D). The density distributions (Figures 4B,D,F) depict the variation and progress of the average GY for each TPE in India, which generally tended to be lower in TPE 2 (Figure 4D) than in TPEs 1 and 3. 


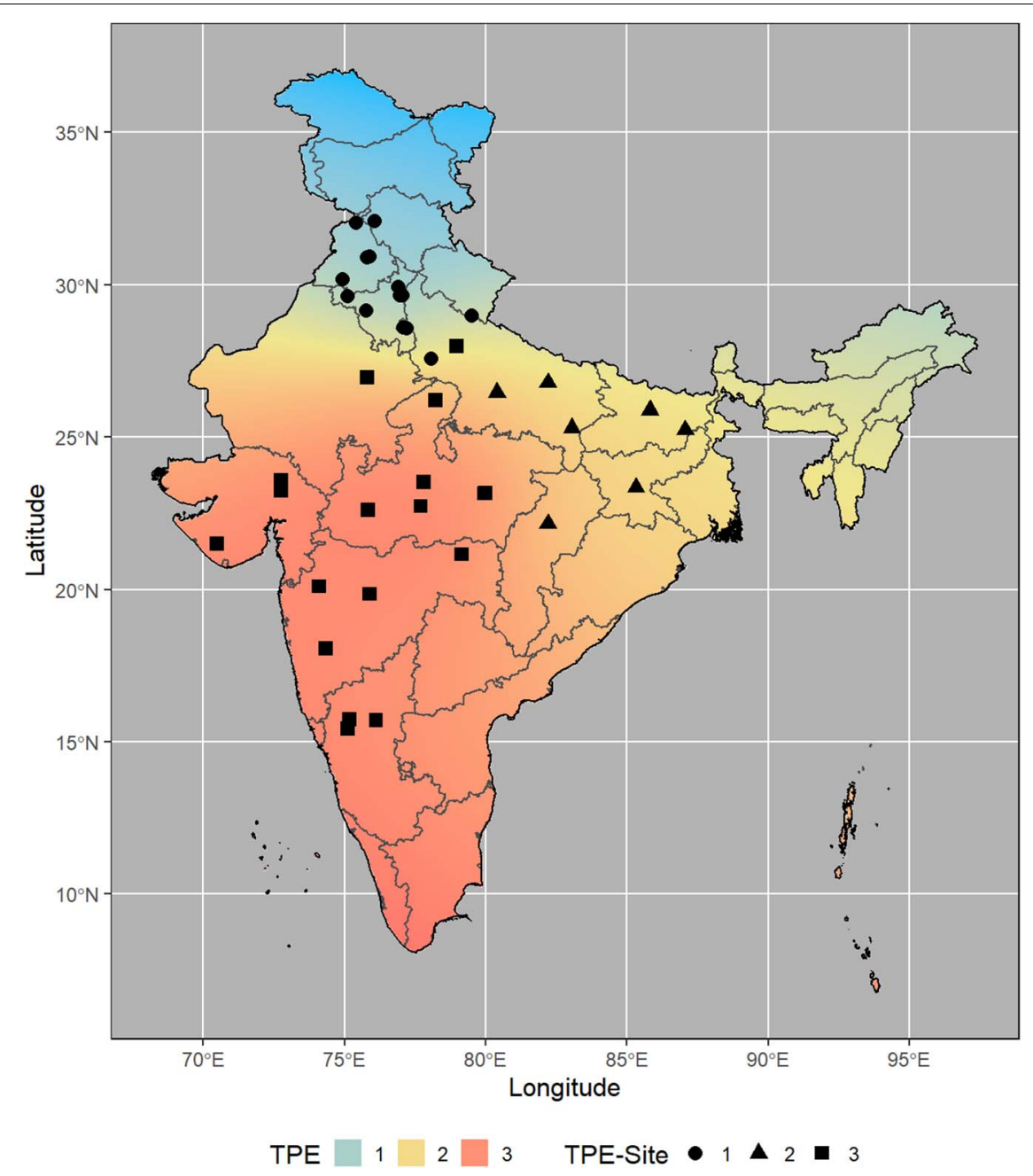

FIGURE 2 | Location of Elite Spring Wheat Yield Trials sites within each Target Population of Environments (TPE) in India.

TABLE 3 | Variance components, phenotypic variance $\left(V_{Z}\right)$, heritability $\left(H^{2}\right)$, genetic correlation $(r)$, correlated response (CR), and direct response to selection (DR) of Elite Spring Wheat Yield Trials (ESWYT) grown from 2001 to 2016 across sites and Target Population of Environments (TPEs).

\begin{tabular}{|c|c|c|c|c|c|c|c|c|c|c|c|c|c|}
\hline Year & ESWYT & $\mathrm{E}(\mathrm{TPE})$ & G & $G^{\star} T P E$ & $G^{\star} E(T P E)$ & $R(E)$ & $S B\left(E^{\star} R\right)$ & Residual & $\mathbf{v}_{z}$ & $\mathrm{H}^{2}$ & $r$ & CR & DR \\
\hline 2005 & 26 & 0.7807 & 0.0312 & 0.01168 & 0.1298 & 0.00358 & 0.05208 & 0.2705 & 0.07 & 0.62 & 0.42 & 0.41 & 0.16 \\
\hline 2007 & 28 & 1.0941 & 0.0222 & 0.03947 & 0.1228 & 0.01797 & 0.03856 & 0.1703 & 0.08 & 0.79 & 0.47 & 0.50 & 0.22 \\
\hline 2008 & 29 & 3.3262 & 0.0126 & 0 & 0.1749 & 0.02885 & 0.07857 & 0.09306 & 0.03 & 0.41 & 0.41 & 0.36 & 0.07 \\
\hline 2009 & 30 & 0.5347 & 0.0169 & 0.00117 & 0.1189 & 0.00566 & 0.02894 & 0.108 & 0.03 & 0.59 & 0.54 & 0.49 & 0.10 \\
\hline 2012 & 33 & 1.1673 & 0.0392 & 0.01684 & 0.2073 & 0.00638 & 0.03984 & 0.1878 & 0.07 & 0.80 & 0.51 & 0.47 & 0.21 \\
\hline 2013 & 34 & 2.1213 & 0.0163 & 0.02693 & 0.28 & 0.05409 & 0.04214 & 0.2104 & 0.07 & 0.66 & 0.90 & 0.89 & 0.17 \\
\hline 2014 & 35 & 0.6268 & 0.0344 & 0.0083 & 0.1122 & 0.00852 & 0.04085 & 0.1364 & 0.05 & 0.79 & 0.54 & 0.48 & 0.18 \\
\hline 2015 & 36 & 0.632 & 0.0242 & 0.01403 & 0.1412 & 0.00112 & 0.03473 & 0.1841 & 0.06 & 0.68 & 0.28 & 0.24 & 0.16 \\
\hline 2016 & 37 & 2.2357 & 0.022 & 0.00963 & 0.1416 & 0.02188 & 0.03929 & 0.2225 & 0.04 & 0.70 & 0.56 & 0.52 & 0.15 \\
\hline
\end{tabular}

E, Variance of Environments (Sites); G, Genotypic variance; R, Reps; SB, Sub-blocks. 
TABLE 4 | Average variance components of Elite Spring Wheat Yield Trials (ESWYT) grown from 2001 to 2016 by Target Population of Environments (TPE).

\begin{tabular}{|c|c|c|c|c|c|c|c|}
\hline TPE & G & $\mathbf{E}$ & $G^{\star} E$ & $R^{\star} \mathrm{SB}(\mathrm{E})$ & SB(R) & Residual & Average sites \\
\hline 1 & 0.056 & 1.342 & 0.164 & 1.405 & & 0.232 & 6.8 \\
\hline 2 & 0.075 & 1.074 & 0.138 & 1.611 & 0.094 & 0.167 & 2.5 \\
\hline 3 & 0.033 & 1.855 & 0.139 & 1.954 & & 0.202 & 5.1 \\
\hline
\end{tabular}

G, Genotypic variance; E, Variance of Environments (Sites); R, Reps; SB, Sub-blocks.

TABLE 5 | Average phenotypic and genetic correlations between Target Population of Environments (TPEs).

\begin{tabular}{|c|c|c|c|c|}
\hline \multicolumn{5}{|c|}{ Phenotypic correlation } \\
\hline & 1 & 2 & 3 & \\
\hline 1 & 1 & 0.29 & 0.31 & \\
\hline 2 & & 1 & 0.26 & \\
\hline 3 & & & 1 & \\
\hline \multicolumn{5}{|c|}{ Genetic correlation } \\
\hline & 1 & 2 & & 3 \\
\hline 1 & 1 & 0.56 & & 0.63 \\
\hline 2 & & 1 & & 0.60 \\
\hline 3 & & & & 1 \\
\hline
\end{tabular}

\section{DISCUSSION}

The characterization of targeted breeding regions by defining TPEs is fundamental in designing strategies for any plant breeding program (Atlin et al., 2000) and paramount for CIMMYT, which seeks to develop wheat germplasm with high and stable yields for smallholder farmers worldwide. In South Asia-home to more than 300 million undernourished people and whose inhabitants consume over 100 million tons of wheat each year-92\% of the varieties released contain CIMMYT breeding contributions and half of the spring bread wheat varieties are direct releases of CIMMYT breeding lines (Lantican et al., 2016).

In the present research, we used available climate and soil data to define three main TPEs in India, the largest wheat producer in South Asia (USDA, 2020) and one of the main breeding targets for CIMMYT. These TPEs coincided with the three main geographical zones in India: TPE 1, representing the NWPZ; TPE 2, the NEPZ; and TPE 3, the CPZ. This characterization corresponds to data provided by the Government of India and represents more than 28 million ha, which is equivalent to over 97\% of India's total wheat (Singh et al., 2019).

Based on the GY data (Figure 4) and the recorded minimum temperature (Table 2), which is a critical parameter for wheat production (Asseng et al., 2015), TPE 1 is associated with optimum wheat-growing conditions, whereas wheat grown in TPE 2 and TPE 3 is subject to stress caused by higher temperatures or drought. Higher temperatures combined with higher rates of relative humidity, as occurs in TPE 2, can cause the development of leaf diseases other than rusts. Indeed, one of the most important leaf diseases in NEPZ (TPE 2) is spot blotch caused by the fungi Bipolaris sorokiniana, which can cause significant GY losses (Devi et al., 2018). Similarly, given the lower average temperatures in the NWPZ (TPE 1), yellow rust caused by Puccinia striiformis f. sp. tritici is currently the most relevant disease for that region, even though all three types of wheat rust occur throughout India's wheat-growing areas (Joshi et al., 2007).

Regarding soil characteristics, TPE 1 can be classified as a loam type of soil, TPE 2 as clay loam, and TPE 3 as clay type of soil (Soil Science Division Staff, 2017). In general, the soil of the three TPEs can be considered of medium texture. The cation exchange capacity of TPE 3 indicates a higher availability of essential minerals for the plants than in TPEs 1 and 2 (Table 2). The available soil water capacity was lower in TPE 3 , which may be due in part to the greater proportion of coarse fragments in its soils (Table 2), meaning that wheat crops in this environment may suffer drought stress more frequently. This can be aggravated by the suboptimal irrigation common in TPE 3 and occasionally in TPE 2 due to lack of water (Joshi et al., 2007).

CIMMYT target environment characterizations date back to its precursor organization, the joint Mexico-Rockefeller Foundation Office of Special Studies, which operated in the 1940s, and were initially restricted to Mexico but became global with the Center's formal establishment in the 1960s. Target environment definitions at that time were based on required traits, the need for yield stability, and the diversification of production systems. In the 1970s, 15 agroecological zones were defined. In the 1980s, CIMMYT redefined those agroecological zones and identified instead 12 wheat MEs, defined as broad, not necessarily contiguous but frequently transcontinental, areas with similar biotic and abiotic stresses, cropping system requirements, and consumer preferences (Rajaram et al., 1994); six each for spring and winter wheat growth habits. DeLacy et al. (1993) showed that the major discrimination factors among MEs were latitude and the presence/absence of stresses. Hodson and White (2007) used geospatial criteria to refine ME definitions and found that, in India, ME1 (high yield potential, irrigated) and ME5 (lower yield potential, irrigated, and temperature stressed) were predominant. From our results, and given the geographical projection reported by Hodson and White (2007), TPE 1 overlaps with ME1 and TPE 2 with ME5, whereas TPE 3 relates to ME4 (lower yield potential, drought stressed). The MEs can be broad and transcontinental, making latitude a fundamental factor, but we defined the TPEs in India at the regional level. In fact, when ME1 was first defined in India, it encompassed the NWPZ (TPE 1) and part of the NEPZ (TPE 2), whereas in our analysis, these two regions appear to be different in terms of climate and some soil characteristics (Table 2). Similarly, ME5 
TABLE 6 | Variance components, phenotypic variance $\left(V_{Z}\right)$, heritability $\left(\mathrm{H}^{2}\right)$ across selection environments (SEs), and direct response to selection (DR) of Elite Spring Wheat Yield Trials (ESWYT) grown from 2001 to 2016 across SEs.

\begin{tabular}{|c|c|c|c|c|c|c|c|c|c|}
\hline Year & ESWYT & G & $G * S E$ & $R^{\star} S B$ & $\mathrm{R}^{\star} \mathrm{SB}(\mathrm{SE})$ & Residual & $\operatorname{Var}_{Z}$ & $\mathbf{H}^{2}$ & DR \\
\hline 2001 & 22 & 0.4496 & & 0.15857 & & 0.40665 & 0.65 & & 0.56 \\
\hline 2005 & 26 & 0.18293 & 0 & & 0.09811 & 0.37411 & 0.28 & 0.66 & 0.35 \\
\hline 2006 & 27 & 0.17917 & 0.06219 & & 0.36282 & 0.2721 & 0.28 & 0.64 & 0.34 \\
\hline 2007 & 28 & 0.05154 & 0.0706 & & 0.14638 & 0.10379 & 0.08 & 0.63 & 0.18 \\
\hline 2008 & 29 & 0.02129 & 0.05575 & & 0.12668 & 0.07947 & 0.04 & 0.53 & 0.11 \\
\hline 2009 & 30 & 0.03146 & 0 & & 0.05682 & 0.10463 & 0.05 & 0.64 & 0.14 \\
\hline 2010 & 31 & 0.1926 & & 0.00927 & & 0.18273 & 0.28 & & 0.36 \\
\hline 2011 & 32 & 0.03193 & 0.02453 & & 0.06503 & 0.08938 & 0.06 & 0.58 & 0.14 \\
\hline 2012 & 33 & 0.09795 & 0.06943 & & 0.09896 & 0.04184 & 0.14 & 0.68 & 0.26 \\
\hline 2013 & 34 & 0.02496 & 0.06268 & & 0.08571 & 0.08912 & 0.05 & 0.48 & 0.11 \\
\hline 2014 & 35 & 0.03325 & 0.02416 & & 0.08932 & 0.07997 & 0.05 & 0.67 & 0.15 \\
\hline 2015 & 36 & 0.02962 & 0.07571 & & 0.08995 & 0.11402 & 0.06 & 0.53 & 0.12 \\
\hline 2016 & 37 & 0.03387 & 0.04699 & & 0.06042 & 0.05311 & 0.05 & 0.65 & 0.15 \\
\hline Mean & & 0.1046 & 0.0447 & 0.0839 & 0.1164 & 0.1531 & 0.14 & 0.73 & 0.28 \\
\hline
\end{tabular}

G, Genotypic variance; E, Variance of Environments (Sites); R, Reps; SB, Sub-blocks.

TABLE 7 | Phenotypic variance $\left(V_{z}\right)$, heritability for the TPE $\left(H^{2}\right.$ tpe), genetic correlations $(r)$, correlated response $(C R)$, by selecting across selection environments and direct response (DR) to selection in each Target Population of Environments (TPE).

\begin{tabular}{|c|c|c|c|c|c|c|c|c|c|c|c|c|c|c|c|c|}
\hline \multirow[b]{2}{*}{ Year } & \multirow[b]{2}{*}{ ESWYT } & \multicolumn{5}{|c|}{ TPE 1} & \multicolumn{5}{|c|}{ TPE 2} & \multicolumn{5}{|c|}{ TPE 3} \\
\hline & & $\mathbf{v}_{z}$ & $\mathrm{H}^{2}$ tpe & $r$ & CR & DR & $\mathbf{v}_{z}$ & $\mathrm{H}^{2}$ tpe & $\mathbf{r}$ & CR & DR & $\mathbf{v}_{z}$ & $\mathrm{H}^{2} t p e$ & $r$ & CR & DR \\
\hline 2001 & 22 & 0.14 & 0.3 & & & 0.11 & 0.15 & 0.67 & & & 0.26 & 0.09 & 0.34 & & & 0.1 \\
\hline 2005 & 26 & 0.11 & 0.54 & 0.65 & 0.72 & 0.18 & 0.06 & 0.64 & 0.57 & 0.58 & 0.16 & 0.10 & 0.2 & -0.09 & -0.16 & 0.06 \\
\hline 2006 & 27 & 0.07 & 0.41 & 0.38 & 0.48 & 0.11 & 0.2 & 0.22 & 0.99 & 1.70 & 0.1 & 0.05 & 0 & & & 0.00 \\
\hline 2007 & 28 & 0.06 & 0.57 & 0.39 & 0.41 & 0.14 & 0.72 & 0.44 & 0.84 & 1.01 & 0.37 & 0.10 & 0.58 & -0.04 & -0.04 & 0.18 \\
\hline 2008 & 29 & 0.05 & 0.22 & 0.9 & 1.55 & 0.05 & 0.16 & 0.2 & 0.06 & 0.10 & 0.08 & 0.05 & 0 & & & 0.00 \\
\hline 2009 & 30 & 0.04 & 0.46 & 0.42 & 0.50 & 0.1 & 0.16 & 0.2 & 0.99 & 1.79 & 0.08 & 0.06 & 0.33 & 0.14 & 0.20 & 0.08 \\
\hline 2010 & 31 & 0.14 & 0.56 & & & 0.21 & 0.08 & 0.25 & & & 0.07 & 0.08 & 0.46 & & & 0.13 \\
\hline 2011 & 32 & 0.12 & 0.69 & 0.99 & 0.83 & 0.24 & 0.08 & 0.14 & 0.45 & 0.92 & 0.04 & 0.09 & 0.63 & 0.63 & 0.61 & 0.19 \\
\hline 2012 & 33 & 0.10 & 0.66 & 0.45 & 0.45 & 0.21 & 0.09 & 0.38 & 0.16 & 0.21 & 0.11 & 0.11 & 0.64 & 0.59 & 0.61 & 0.21 \\
\hline 2013 & 34 & 0.14 & 0.64 & 0.82 & 0.71 & 0.24 & 0.12 & 0.06 & 0.99 & 2.86 & 0.02 & 0.08 & 0.18 & 0.7 & 1.13 & 0.05 \\
\hline 2014 & 35 & 0.08 & 0.72 & 0.54 & 0.52 & 0.21 & 0.11 & 0.49 & 0.49 & 0.58 & 0.16 & 0.08 & 0.53 & 0.46 & 0.52 & 0.15 \\
\hline 2015 & 36 & 0.09 & 0.66 & 0.32 & 0.29 & 0.2 & 0.2 & 0.65 & 0.03 & 0.03 & 0.29 & 0.10 & 0.17 & 0.13 & 0.23 & 0.05 \\
\hline 2016 & 37 & 0.09 & 0.62 & 0.53 & 0.54 & 0.18 & 0.08 & 0.18 & 0.29 & 0.55 & 0.05 & 0.07 & 0.42 & 0.55 & 0.68 & 0.11 \\
\hline Mean & & 0.1 & 0.54 & 0.58 & 0.64 & 0.17 & 0.18 & 0.39 & 0.60 & 0.94 & 0.16 & 0.08 & 0.38 & 0.34 & 0.42 & 0.11 \\
\hline
\end{tabular}

ESWYT, Elite Spring Wheat Yield Trials.

included also the CPZ, whereas in our analysis, this appeared to be classified as TPE 3 .

The average $H^{2}$ in each TPE in all cases was lower than in the SEs. Given that each ESWYT cycle varies from year to year, estimations of GE variance that include not only the SE but also the year effect are not possible due to the lack of connectivity between cycles. Nonetheless, we have somewhat addressed this constraint by analyzing various years of data consisting of "good" and "bad" years in the SEs and TPEs; the year effect is also implied in the pedigree-based prediction models. The average $H^{2}$ across sites in India considering TPE subdivision was similar to that of the $H^{2}$ across SEs owing to the fact that many more environments are present across the TPEs than in the SE, and the response of the genotype within the TPEs becomes $G+G^{*} T P E$, thus passing this term to the numerator of the $H^{2}$ formula and so contributing to the response to selection by separating $\mathrm{G}^{*} \mathrm{TPE}$ from $\mathrm{G}^{*} \mathrm{E}$ (Atlin et al., 2000).

The extent of the genotype-by-environment [G*E(TPE)] interaction variance was more than five times greater than that of G across TPEs, whereas across SEs, the G*SE variance was lower than the $G$ variance. Similarly, the average genotypic variance was more than three times greater across SEs than across TPEs. Furthermore, the size of $\mathrm{G}^{*} \mathrm{E}$ in each TPE was substantially lower when compared to the one across all sites in India [ $\left.\mathrm{G}^{*} \mathrm{E}(\mathrm{TPE})\right]$, which indicates that the subdivision in TPEs is meaningful by reducing the extent of the genotype-by-environment.

Additionally, the fact that the variance of $G$ increases substantially within each TPE when compared with pooled 
TABLE 8 | Estimated variance components ( \pm standard deviation of the estimator) from the pedigree-based prediction models for each selection environment (SE) in CIMMYT-Obregón and their proportion of variance relative to the total (PTV) of the models.

\begin{tabular}{|c|c|c|c|c|c|c|c|}
\hline \multirow[b]{2}{*}{ SE } & \multirow[b]{2}{*}{ Component $^{a}$} & \multicolumn{3}{|c|}{ Model } & \multicolumn{3}{|c|}{ PTV by model (\%) } \\
\hline & & AE & $A E-A x E$ & AE-AxE-W-AxW & $\mathrm{AE}$ & $A E-A x E$ & AE-AxE-W-AxW \\
\hline \multirow[t]{6}{*}{ B5IR } & $V_{A}$ & $0.06 \pm 0.003$ & $0.05 \pm 0.003$ & $0.05 \pm 0.004$ & 3.4 & 3.0 & 7.9 \\
\hline & $V_{E}$ & $1.49 \pm 0.409$ & $1.56 \pm 0.489$ & $0.29 \pm 0.127$ & 92.4 & 92.1 & 43.2 \\
\hline & $\mathrm{V}_{A E}$ & & $0.05 \pm 0.003$ & $0.04 \pm 0.004$ & & 2.8 & 5.3 \\
\hline & $V_{W}$ & & & $0.24 \pm 0.096$ & & & 36.3 \\
\hline & $V_{A W}$ & & & $0.01 \pm 0.002$ & & & 1.9 \\
\hline & $\mathrm{V}_{r}$ & $0.07 \pm 0.001$ & $0.04 \pm 0.002$ & $0.04 \pm 0.002$ & 4.2 & 2.1 & 5.4 \\
\hline \multirow[t]{6}{*}{ B2IR } & $V_{A}$ & $0.06 \pm 0.006$ & $0.05 \pm 0.005$ & $0.04 \pm 0.006$ & 3.8 & 3.2 & 3.0 \\
\hline & $\mathrm{V}_{E}$ & $1.37 \pm 0.437$ & $1.31 \pm 0.371$ & $1.07 \pm 0.362$ & 88.1 & 86.6 & 75.4 \\
\hline & $\mathrm{V}_{A E}$ & & $0.07 \pm 0.007$ & $0.04 \pm 0.006$ & & 4.7 & 2.7 \\
\hline & $V_{W}$ & & & $0.15 \pm 0.082$ & & & 10.6 \\
\hline & $V_{A W}$ & & & $0.03 \pm 0.005$ & & & 2.4 \\
\hline & $\mathrm{V}_{r}$ & $0.12 \pm 0.004$ & $0.08 \pm 0.004$ & $0.08 \pm 0.004$ & 8.0 & 5.4 & 5.9 \\
\hline \multirow[t]{6}{*}{ BLHT } & $\mathrm{V}_{A}$ & $0.07 \pm 0.006$ & $0.06 \pm 0.006$ & $0.04 \pm 0.006$ & 7.4 & 6.2 & 4.0 \\
\hline & $V_{E}$ & $0.81 \pm 0.241$ & $0.76 \pm 0.23$ & $0.65 \pm 0.202$ & 80.6 & 77.8 & 74.6 \\
\hline & $\mathrm{V}_{A E}$ & & $0.09 \pm 0.009$ & $0.08 \pm 0.008$ & & 9.2 & 9.6 \\
\hline & $V_{W}$ & & & $<0.00 \pm 0.001$ & & & 0.2 \\
\hline & $\mathrm{V}_{A W}$ & & & $0.03 \pm 0.007$ & & & 4.0 \\
\hline & $\mathrm{V}_{r}$ & $0.12 \pm 0.003$ & $0.07 \pm 0.005$ & $0.07 \pm 0.004$ & 12.0 & 6.8 & 7.6 \\
\hline \multirow[t]{6}{*}{ F5IR } & $\mathrm{V}_{A}$ & $0.05 \pm 0.004$ & $0.04 \pm 0.004$ & $0.03 \pm 0.004$ & 3.0 & 1.6 & 2.4 \\
\hline & $\mathrm{V}_{E}$ & $1.41 \pm 0.493$ & $2.13 \pm 0.795$ & $0.54 \pm 0.324$ & 91.7 & 94.1 & 41.8 \\
\hline & $\mathrm{V}_{A E}$ & & $0.04 \pm 0.004$ & $0.02 \pm 0.004$ & & 1.6 & 1.9 \\
\hline & $V_{W}$ & & & $0.62 \pm 0.42$ & & & 47.8 \\
\hline & $V_{A W}$ & & & $0.02 \pm 0.002$ & & & 1.3 \\
\hline & $\mathrm{V}_{r}$ & $0.08 \pm 0.002$ & $0.06 \pm 0.003$ & $0.06 \pm 0.003$ & 5.3 & 2.7 & 4.8 \\
\hline \multirow[t]{6}{*}{ FDRT } & $\mathrm{V}_{A}$ & $0.04 \pm 0.003$ & $0.03 \pm 0.003$ & $0.03 \pm 0.004$ & 3.3 & 2.1 & 3.6 \\
\hline & $V_{E}$ & $1.07 \pm 0.338$ & $1.42 \pm 0.46$ & $0.53 \pm 0.195$ & 89.7 & 90.9 & 59.9 \\
\hline & $\mathrm{V}_{A E}$ & & $0.07 \pm 0.005$ & $0.06 \pm 0.005$ & & 4.6 & 6.6 \\
\hline & $V_{W}$ & & & $0.22 \pm 0.095$ & & & 24.1 \\
\hline & $\mathrm{V}_{A W}$ & & & $0.01 \pm 0.002$ & & & 1.6 \\
\hline & $\mathrm{V}_{r}$ & $0.08 \pm 0.002$ & $0.04 \pm 0.002$ & $0.04 \pm 0.002$ & 7.0 & 2.3 & 4.2 \\
\hline
\end{tabular}

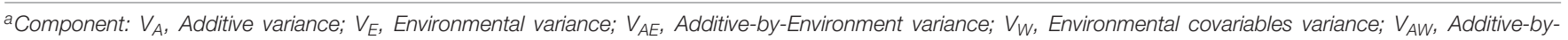
Environmental covariables variance; and $V_{r}$, Residual Variance.

variance across all sites in India indicates that there is a part of $G$ that can be further exploited in each TPE. Altogether, these results suggest that greater gains can be achieved by targeting selection in the TPE than without TPE subdivision because of a higher precision given that $H^{2}$ disregarding the TPEs is substantially lower than the one including the TPEs in the mixed model. Although the size of the G TPE variance is smaller than that of the $\mathrm{G}^{*} \mathrm{E}(\mathrm{TPE})$, the size of $\mathrm{G}^{*} \mathrm{E}(\mathrm{TPE})$ relative to $\mathrm{G}$ is substantial (Atlin et al., 2000).

The observed phenotypic and genetic correlations between TPEs suggest that line performance information from one TPE can be used to make inferences about performance in others. This result is useful in the potential design of testing strategies for TPEs, although our results from the variance components still suggest that response to selection can be greater if TPE-targeted decisions are made from the data derived across SEs.

Regarding the CR, the results indicated that with TPE subdivision, the efficiency can be higher in TPE 1 and TPE 2 than across India. The CR for TPE 3 was comparable to that of the analysis across sites, but not higher. Ideally, for the CR to be at its maximum, the $H^{2}$ in the SE needs to be higher than in the TPEs, and the genetic correlation needs to be close to unity as possible; however, these conditions are not necessarily met (Searle, 1965). Genetic correlations are highly influential in the CR because its changes are directly related to the opportunities of achieving an indirect response by selecting in the SE for the TPEs (Cooper and DeLacy, 1994). In our results, the $H^{2}$ in the SE is higher than in TPEs, and the genetic correlations are, in average, of medium magnitude, which altogether has permitted to make genetic progress in the TPEs. It is important to note that, when calculating the correlated response to selection (indirect selection efficiency), it is assumed that the selection intensity in the SE is the same as in the TPEs (Falconer, 1952; Searle, 1965) for which the observed values may vary, considering that there is higher selection intensity in the SE, going from an initial 9,000 lines to the 49 lines finally included in each ESWYT. 


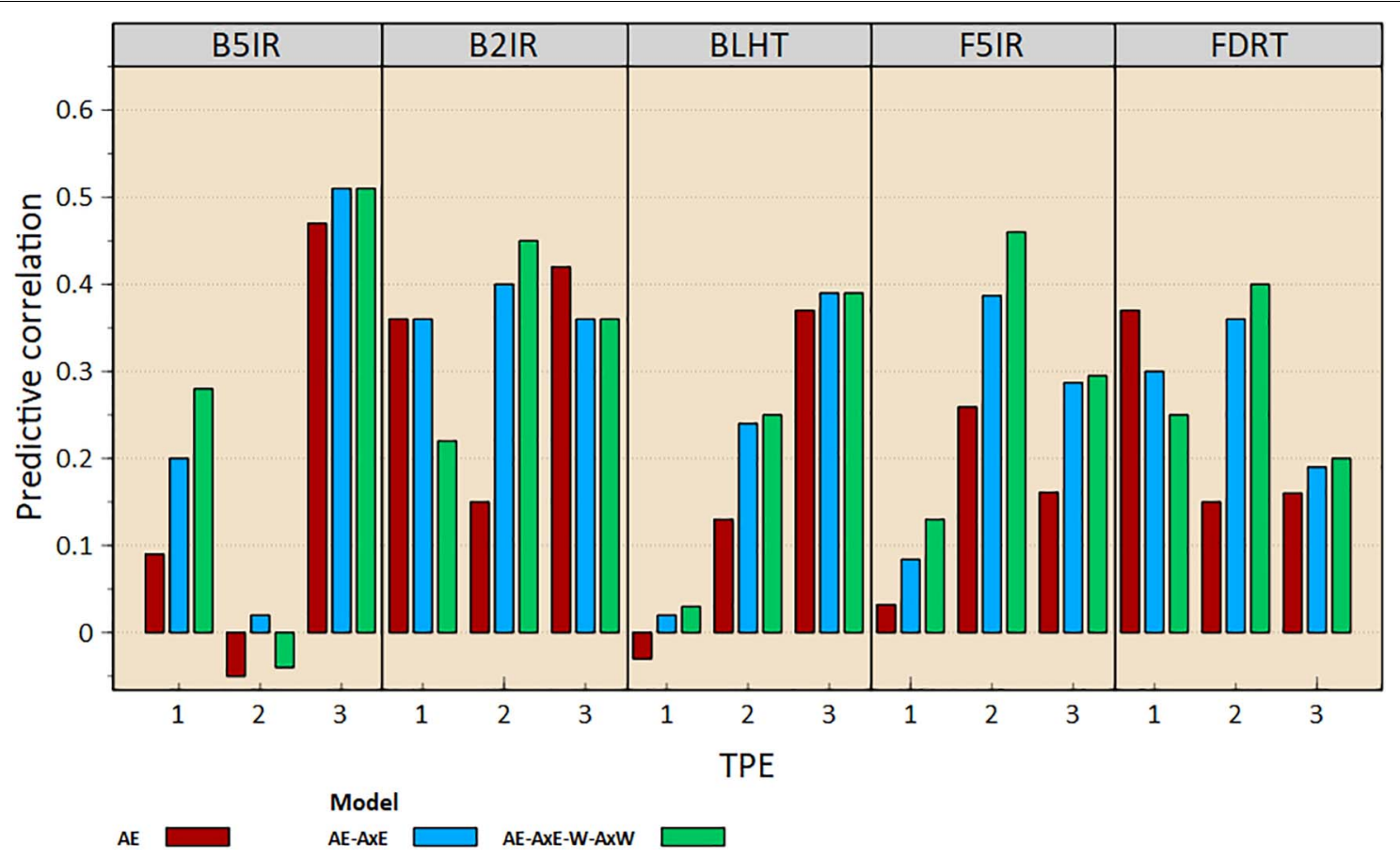

FIGURE 3 | Pedigree-based predictive correlations between selection environments at the CIMMYT-Ciudad Obregón research station and a Target Population of Environments (TPE) in India for the 2016 cycle of the International Elite Spring Wheat Trial.

The results derived from the DR indicate that, in terms of selection intensity ( $i$ ), to achieve a selection response across TPEs and in each of the TPEs similar to the one in the SEs, $i$ would need to be proportionally higher in each TPE in relation to the SE. This is largely due to the fact that $H^{2}$ in individual TPEs is lower than $H^{2}$ across SEs, so gains in TPEs can be raised by improving TPE testing conditions, thus increasing $H^{2}$. One of the aspects that contribute to maintain high-medium $H^{2}$ in the SE and that are standard practices are: the mechanized operations (planting, crop management, and harvest), adequate management of the irrigation water including drip irrigation systems, and a crop rotation strategy to uniformize soil moisture during May-September prior to the wheat-planting season in November.

In applying pedigree-based prediction models to assess the predictive ability of SEs, a large portion of total variance was accounted for by the main environmental effects (Table 5), which in this case considers previous information of SEs and TPEs and the TPE/SE-year combinations. In most cases, environmental variance fell significantly with the inclusion of MVs, which indicates this information contains, as expected, an explainable proportion of the environmental variance and the year effect. The SEs in which the MVs did not contribute to total phenotypic variance were BLHT and B2IR, indicating that the major source of variation within these SEs is given by the spatial features of the environment rather than by year-to-year MV variation. In agreement with previous findings, the inclusion of the GE term in the prediction models and environmental covariables generally tends to increase the prediction accuracy of the models (Jarquín et al., 2014; Pérez-Rodríguez et al., 2015; Cuevas et al., 2017).

Based on the pedigree-based predictions (Figure 3), TPE 1 is mainly associated with SEs B5IR and B2IR, and FDRT. The SEs that displayed higher association with TPE 2 were B2IR, F5IR, and FDRT, while B5IR, B2IR, and BLHT displayed higher association with TPE 3. The patterns we found of correlated, and direct, response to selection are being used to select germplasm included each year in ESWYT, which is targeted to TPE 1 and requires lines of normal maturity, rather than the early maturing lines desirable for TPEs 2 and 3.

Previous findings have indicated that simulated SEs at CIMMYT-Ciudad Obregón correlate with international sites and that this has resulted in GY genetic gains in target regions (Trethowan et al., 2002; Lillemo et al., 2004; Tadesse et al., 2010; Manès et al., 2012; Crespo-Herrera et al., 2017). The possibility of evaluating large numbers of lines for GY over different SEs has created an opportunity to develop and adapt germplasm for regions beyond the breeding site. This study suggests expanding the scope of such opportunities. For instance, thanks to CIMMYT's collaboration with the Government of India and financial support from the USAID Feed the Future Innovation Lab on Applied Wheat Genomics at Kansas State University, more than 500 wheat lines that undergo Stage 2 evaluation are now routinely tested at three sites, each in a different India TPE, by the Borlaug Institute for South Asia (BISA sites; Table 1).

Earlier testing of lines in TPEs, coupled with SE data, could raise genetic gains in ESWYT germplasm (Sharma et al., 2012; 

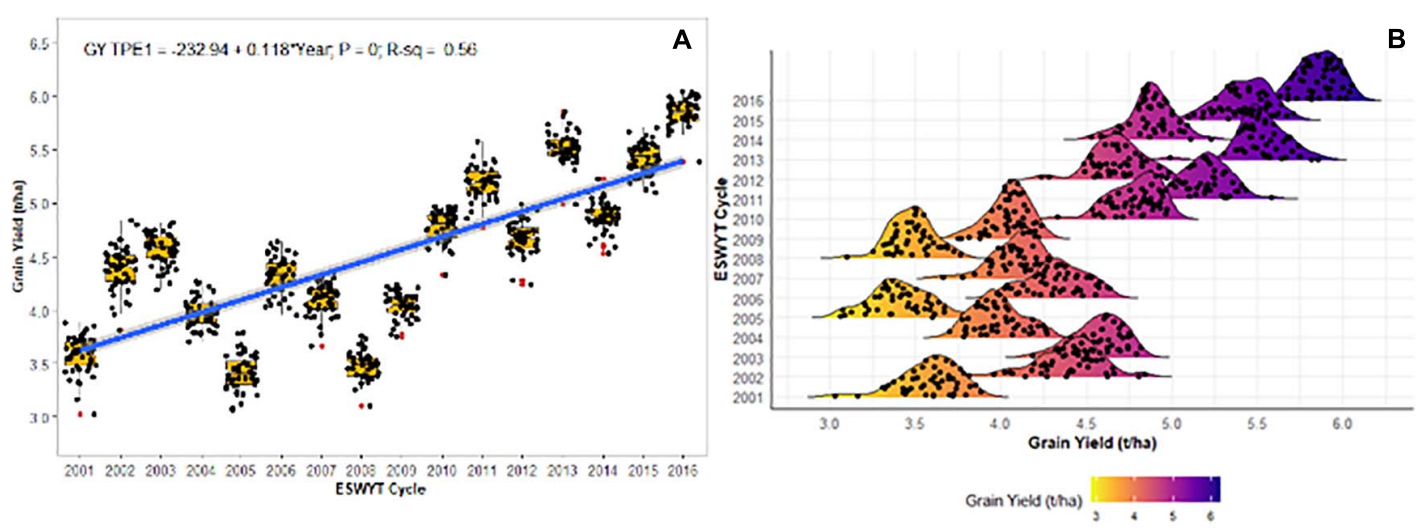

B
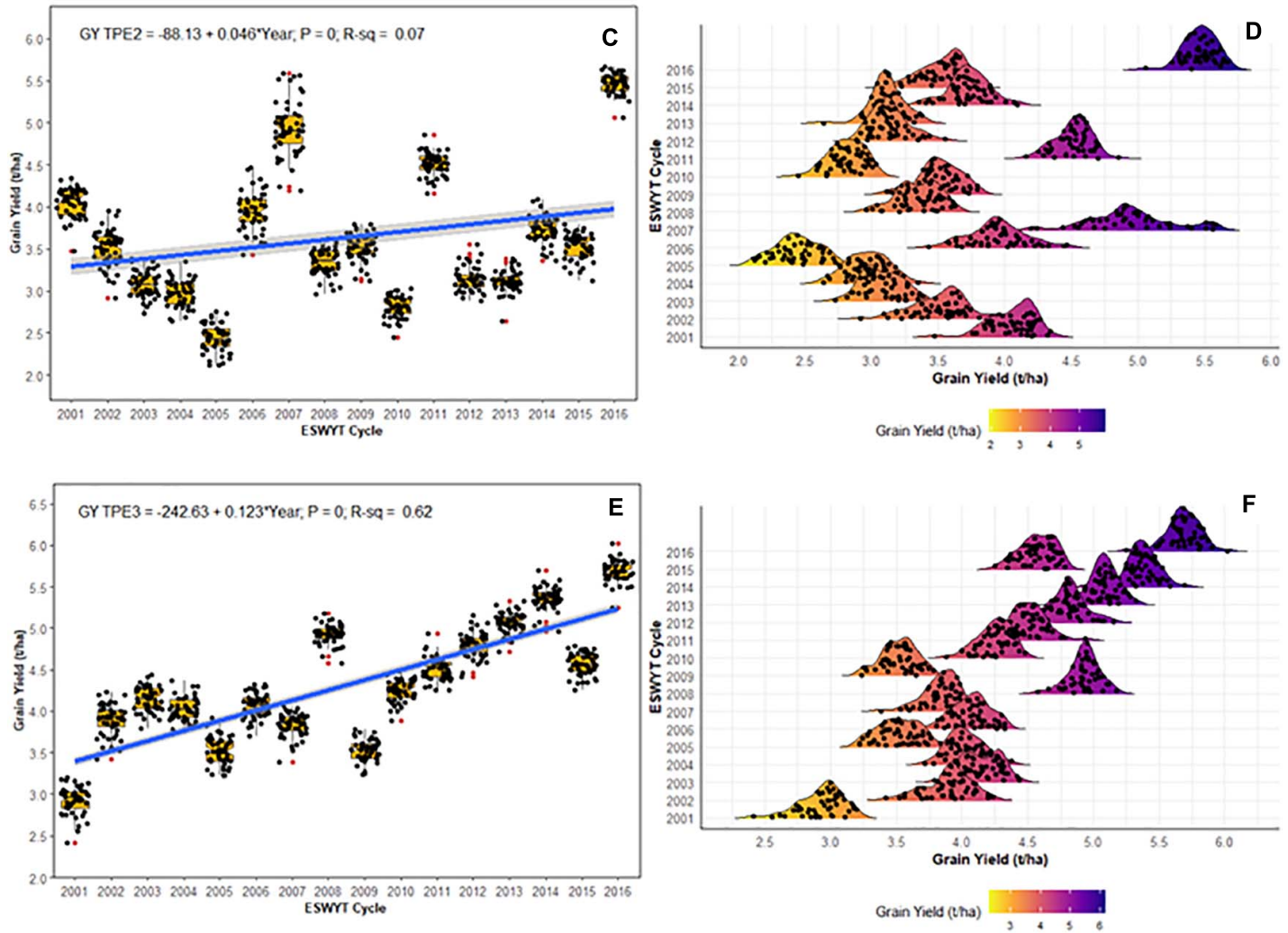

FIGURE 4 | Grain yield (GY) progress and density distribution of Elite Spring Wheat Yield Trials (ESWYT) germplasm from 2001 to 2016 crop cycles in the Target Population of Environments (TPE) in India. (A,B) GY progress and density distribution for TPE 1; (C,D) GY progress and density distribution for TPE 2; (E,F) GY progress and density distribution for TPE 3.

Crespo-Herrera et al., 2017), since more information from the TPEs could be available to make crossing and selection decision of parental lines.

In general, the current breeding strategy justifies the indirect selection in the SE for the TPEs, given the magnitude of $H^{2}$, the relative size of the $G$ and $G^{*} E$ variances, the magnitude of $D R$ and its implications on the selection intensity, and the fact that a centralized breeding operation that has for a long term delivered genetic gains to India is more resource efficient. Nonetheless, current advances in statistical methods and selection tools may permit a fine-tuning of the testing strategy, for instance, one possible option is to evaluate Stage 1 lines in all the SEs to make selections for Stage 2 evaluations, which also can be conducted in both the SE and TPE. This change would require a modification in trial designs and allocation of resources, as these are limited in both the SE and TPE. Currently, the ESWYT germplasm is tested in the TPEs after 2 or 3 years of testing at CIMMYT-Ciudad Obregón. Hence, earlier information from the TPE can improve the selection for the final ESWYT germplasm and consequently the potential varieties that can be grown in the TPEs.

Based on our results, greater gains in GY were achieved in TPE $1(118 \mathrm{~kg} / \mathrm{ha} /$ year $)$ and TPE $3(123 \mathrm{~kg} / \mathrm{ha} /$ year $)$ than in TPE 
$2(46 \mathrm{~kg} / \mathrm{ha} /$ year $)$ over the period we studied. ESWYT lines are bred for optimal environments and show better adaptation in TPE 1 and TPE 3. In TPE 2, yield gains are possibly lower due to a shorter growing season with continuous and terminal heat stress, where the germplasm requires some degree of earliness to cope with heat stress (Mondal et al., 2013). These germplasm requirements limit the adaptation of ESWYT lines intended for optimal conditions where earliness is not required due the crop cycle duration. Another annually distributed CIMMYT trial, the International Heat Tolerant Wheat Yield Trial (HTWYT), should feature lines better adapted to TPE 2. The HTWYT lines are selected based on their performance under heat stress with the additional restriction that their performance is comparable to the main checks for the optimal SE.

Wheat breeding must tackle the yield uncertainties that farmers face due to environmental variations. Golling (2006) estimated an annual benefit in excess of $\$ 140$ million due to more stable wheat yields-independent of gains in genetic yield potential-as a result of breeding research. Yield stability is paramount to smallholder farmers and becoming more important as the earth warms and rainfall grows more erratic. According to Cooper and DeLacy (1994), to develop an understanding of the GE interactions in TPEs, it is important to characterize such TPEs in terms of the key environmental challenges that may lead to the definition of strategies for exploiting the GE interactions. In this study, we defined three TPEs in India based on meteorological and soil characteristics that overlap with the three main wheat production zones in India. Furthermore, the TPEs are associated with a set of SEs at CIMMYT-Ciudad Obregón that have allowed GY gains in the germplasm delivered to the TPEs and across India. The results described herein contribute to an integral strategy to the efficiency of CIMMYT's wheat breeding

\section{REFERENCES}

Asseng, S., Ewert, F., Martre, P., Rotter, R. P., Lobell, D. B., Cammarano, D., et al. (2015). Rising temperatures reduce global wheat production. Nat. Clim. Chang. 5, 143-147. doi: 10.1038/nclimate2470

Atlin, G. N., Baker, R. J., McRae, K. B., and Lu, X. (2000). Selection response in subdivided target regions. Crop Sci. 40, 7-13. doi: 10.2135/cropsci2000.4017

Braun, H.-J., Rajaram, S., and van Ginkel, M. (1996). CIMMYT's approach to breeding for wide adaptation. Euphytica 92, 175-183. doi: 10.1007/BF000 22843

Cooper, M., Byth, D. E., and DeLacy, I. H. (1993a). A procedure to assess the relative merit of classification strategies for grouping environments to assist selection in plant breeding regional evaluation trials. Field Crop Res. 35, 63-74. doi: 10.1016/0378-4290(93)90137-C

Cooper, M., Byth, D. E., DeLacy, I. H., and Woodruff, D. R. (1993b). Predicting grain yield in Australian environments using data from CIMMYT international wheat performance trials. 1. Potential for exploiting correlated response to selection. Field Crop Res. 32, 305-322. doi: 10.1016/0378-4290(93)90039-P

Cooper, M., DeLacy, I., and Eisenman, R. (1993c). "Recent advances in the study of genotype $\times$ environment interactions and their application to plant breeding," in Focused Plant Improvement: Towards Responsible and Sustainable Agriculture, eds B. C. Imrie and J. Hacker (Canberrra, NSW: Australian Convention and Travel Services Pty Ltd), 116-131.

Cooper, M., and DeLacy, I. H. (1994). Relationships among analytical methods used to study genotypic variation and genotype-by-environment interaction program and further ensure the delivery of genetic gains to target environments.

\section{DATA AVAILABILITY STATEMENT}

The datasets presented in this study can be found in online repositories. The names of the repository/repositories and accession number(s) can be found below: http://orderseed. cimmyt.org/iwin-results.php.

\section{AUTHOR CONTRIBUTIONS}

All authors listed have made a substantial, direct and intellectual contribution to the work, and approved it for publication.

\section{ACKNOWLEDGMENTS}

We thank the Bill and Melinda Gates Foundation (BMGF) and the UK Foreign, Commonwealth and Development Office (FCDO; formerly UK aid from the UK Government's Department for International Development, DFID) for supporting CIMMYT's wheat breeding activities through the Delivering Genetic Gains in Wheat (DGGW) Project (OPPGD1389) and the Accelerating Genetic Gains in Maize and Wheat (AGG) project (INV-003439). We are grateful for financial support from USAID through various projects, the Indian Council of Agricultural Research (ICAR), and funders of the CGIAR Research Program on Wheat. We highly appreciate and thank collaborators within the International Wheat Improvement Network for growing the trials and returning data. We thank Mike Listman for editorial input on this manuscript.

in plant breeding multi-environment experiments. Theor. Appl. Genet. 88, 561-572. doi: 10.1007/BF01240919

Cooper, M., DeLacy, I. H., Byth, D. E., and Woodruff, D. R. (1993d). Predicting grain yield in Australian environments using data from CIMMYT international wheat performance trials. 2. The application of classification to identify environmental relationships which exploit correlated response to selection. Field Crop Res. 32, 323-342. doi: 10.1016/0378-4290(93)90 040-T

Cooper, M., and Hammer, G. L. (1996). Plant Adaptation and Crop Improvement. Wallingford: CAB International.

Coster, A. (2012). pedigree: Pedigree functions. R package version 1.4.

Crespo-Herrera, L. A., Crossa, J., Huerta-Espino, J., Autrique, E., Mondal, S., Velu, G., et al. (2017). Genetic yield gains in CIMMYT's international elite spring wheat yield trials by modeling the genotype $\times$ environment interaction. Crop Sci. 57, 789-801. doi: 10.2135/cropsci2016.06. 0553

Crossa, J. (1990). Statistical analyses of multilocation trials. Adv. Agron. 44, 55-85. doi: 10.1016/S0065-2113(08)60818-4

Crossa, J., Fox, P. N., Pfeiffer, W. H., Rajaram, S., and Gauch, H. G. (1991). AMMI adjustment for statistical analysis of an international wheat yield trial. Theor. Appl. Genet. 81, 27-37. doi: 10.1007/BF00226108

Cuevas, J., Crossa, J., Montesinos-López, O. A., Burgueño, J., Pérez-Rodríguez, P., and de los Campos, G. (2017). Bayesian genomic prediction with genotype $\times$ environment interaction kernel models. G3 7, 41-53. doi: 10.1534/g3.116. 035584 
DeLacy, I. H., Fox, P. N., Corbett, J. D., Crossa, J., Rajaram, S., Fischer, R. A., et al. (1993). Long-term association of locations for testing spring bread wheat. Euphytica 72, 95-106. doi: 10.1007/BF00023777

Devi, H. M., Mahapatra, S., and Das, S. (2018). Assessment of yield loss of wheat caused by spot blotch using regression model. Indian Phytopathol. 71, 291-294. doi: 10.1007/s42360-018-0036-9

Falconer, D. S. (1952). The problem of environment and selection. Am. Nat. 86, 293-298. doi: 10.2307/2457811

Golling, D. (2006). Impacts of International Research on Intertemporal Yield Stability in Wheat and Maize: An Economic Assessment. Mexico: CIMMYT.

Hodson, D. P., and White, J. W. (2007). Use of spatial analyses for global characterization of wheat-based production systems. J. Agric. Sci. 145:115.

Jarquín, D., Crossa, J., Lacaze, X., Du Cheyron, P., Daucourt, J., Lorgeou, J., et al. (2014). A reaction norm model for genomic selection using high-dimensional genomic and environmental data. Theor. Appl. Genet. 127, 595-607. doi: 10. 1007/s00122-013-2243-1

Joshi, A. K., Mishra, B., Chatrath, R., Ortiz Ferrara, G., and Singh, R. P. (2007). Wheat improvement in India: Present status, emerging challenges and future prospects. Euphytica 157, 431-446. doi: 10.1007/s10681-007-9385-7

Lantican, M. A., Braun, H.-J., Payne, T. S., Singh, R. P., Sonder, K., Michael, B., et al. (2016). Impacts of International Wheat Improvement Research: 1994-2014. Mexico: CIMMYT.

Lillemo, M., Van Ginkel, M., Trethowan, R. M., Hernandez, E., and Crossa, J. (2005). Differential adaptation of CIMMYT bread wheat to global high temperature environments. Crop Sci. 45, 2443-2453.

Lillemo, M., Van Ginkel, M., Trethowan, R. M., Hernandez, E., and Rajaram, S. (2004). Associations among international CIMMYT bread wheat yield testing locations in high rainfall areas and their implications for wheat breeding. Crop Sci. 44, 1163-1169.

Manès, Y., Gomez, H. F., Puhl, L., Reynolds, M., Braun, H. J., and Trethowan, R. (2012). Genetic yield gains of the CIMMYT international semi-arid wheat yield trials from 1994 to 2010. Crop Sci. 52, 1543-1552.

Mondal, S., Singh, R. P., Crossa, J., Huerta-Espino, J., Sharma, I., Chatrath, R., et al. (2013). Earliness in wheat: a key to adaptation under terminal and continual high temperature stress in South Asia. Field Crop Res. 151, 19-26. doi: 10.1016/j.fcr.2013.06.015

Pérez, P., and de los Campos, G. (2014). Genome-wide regression and prediction with the BGLR statistical package. Genetics 198, 483-495. doi: 10.1534/genetics. 114.164442

Pérez-Rodríguez, P., Crossa, J., Bondalapati, K., De Meyer, G., Pita, F., and de los Campos, G. (2015). A pedigree-based reaction norm model for prediction of cotton yield in multienvironment trials. Crop Sci. 55, 1143-1151. doi: 10.2135/ cropsci2014.08.0577
R Development Core Team (2020). R: A Language and Environment for Statistical Computing, Vol. 1. Vienna: R Foundation for Statistical Computing. 409. doi: 10.1007/978-3-540-74686-7

Rajaram, S., Van Ginkel, M., and Fischer, R. A. (1994). “CIMMYT’s wheat breeding mega-environments (ME)," in Proceedings of the 8th International Wheat Genetic Symposium, eds Z. S. Li and Z. Y. Xin (Beijing), 1101-1106.

Searle, S. R. (1965). The value of indirect selection: I. Mass selection. Biometrics 21:682. doi: 10.2307/2528550

Sharma, R. C., Crossa, J., Velu, G., Huerta-Espino, J., Vargas, M., Payne, T. S., et al. (2012). Genetic gains for grain yield in CIMMYT spring bread wheat across international environments. Crop Sci. 52, 1522-1533.

Singh, G. P. G., Sendhil, R., and Gopalreddy, K. (2019). "Maximization of national wheat productivity: challenges and opportunities," in Current Trends in Wheat and Barley Research and Development, eds S. Sai Prasad, A. Mishra, and G. Singh (Indore: ICAR-Indian Agricultural Research Institute), 214.

Soil Science Division Staff (2017). Soil Survey Manual. Washington, DC: United States Department of Agriculture.

Tadesse, W., Manes, Y., Singh, R. P., Payne, T., and Braun, H. J. (2010). Adaptation and performance of CIMMYT spring wheat genotypes targeted to high rainfall areas of the world. Crop Sci. 50, 2240-2248. doi: 10.2135/cropsci2010.02. 0102

Trethowan, R. M., van Ginkel, M., and Rajaram, S. (2002). Progress in breeding wheat for yield and adaptation in global drought affected environments. Crop Sci. 42:1441. doi: 10.2135/cropsci2002. 1441

USDA (2020). Global Agricultural Information Network. Washington, DC: USDA Foreign Agricultural Service.

Ward, J. H. (1963). Hierarchical grouping to optimize an objective function. J. Am. Stat. Assoc. 58:236. doi: 10.2307/2282967

Wood, S. N. (2003). Thin plate regression splines. J. R. Stat. Soc. B 65, 95-114. doi: $10.2307 / 3088828$

Conflict of Interest: The authors declare that the research was conducted in the absence of any commercial or financial relationships that could be construed as a potential conflict of interest.

Copyright (C) 2021 Crespo-Herrera, Crossa, Huerta-Espino, Mondal, Velu, Juliana, Vargas, Pérez-Rodríguez, Joshi, Braun and Singh. This is an open-access article distributed under the terms of the Creative Commons Attribution License (CC BY). The use, distribution or reproduction in other forums is permitted, provided the original author(s) and the copyright owner(s) are credited and that the original publication in this journal is cited, in accordance with accepted academic practice. No use, distribution or reproduction is permitted which does not comply with these terms. 